\title{
PENGARUH STRATEGI PEMASARAN DAN MARKETING COMMUNICATION TERHADAP BRAND AWARENESS DAN DAMPAKNYA PADA MINAT MENONTON RCTI (RAJAWALI CITRA TELEVISI INDONESIA)
}

\author{
Aldio Dwitama ${ }^{1}$; Rita $^{2}$ \\ ${ }^{1}$ Officer Development Program (ODP), PT. Bank Negara Indonesia \\ Plaza BII Tower 2 Jl. Jalan MH.Thamrin Kav 28-30, Jakarta Pusat, dwitamaaldio@rocketmail.com \\ ${ }^{2}$ Management Department, School of Business Management, BINUS University \\ Jln. K.H. Syahdan No.9, Palmerah, Jakarta Barat 11480, rita_edula@yahoo.co.id
}

\begin{abstract}
At the age of 24, in 2013 (the period of January to December 2013), Rajawali Citra Televisi Indonesia (RCTI) has been retaining the position of market leader with a 17.8\% audience share reached. Based on that, RCTI needs to maintain to foster and expand the public watching interest on their program. This study aims to determine the effect of marketing strategy and marketing communications on brand awareness and the impact on the public watching interest on their program. The method used is associative-survey research methods. Data collection techniques are done by using a questionnaire distributed to the public viewers of RCTI and by making interviews to the Senior Manager. Data analysis techniques used is path analysis. As a result, there is a positive and significant effect of the variables of marketing strategy and marketing communications on brand awareness and the impact on public watching interest on RCTI.
\end{abstract}

Keywords: marketing strategy, marketing communication, brand awareness and interests of watching

\begin{abstract}
ABSTRAK
Di usianya yang ke-24, tahun 2013 (periode Januari-Desember 2013), Rajawali Citra Televisi Indonesia (RCTI) tetap mempertahankan posisi market leader dengan pangsa pemirsa mencapai 17.8\%. Berdasarkan hal tersebut, RCTI harus terus mengelola dan menumbuhkan minat menonton masyarakat pada program televisi mereka. Penelitian ini bertujuan untuk mengetahui pengaruh strategi pemasaran dan komunikasi pemasaran terhadap kesadaran merek dan dampaknya pada minat menonton RCTI. Metode penelitian yang digunakan adalah metode penelitian asosiatif-survey. Tehnik pengumpulan data dengan menggunakan kuisioner yang disebar kepada masyarakat umum yang menyaksikan RCTI dan wawancara kepada Senior Manager. Tehnik analisis data dengan analisis jalur. Hasilnya terdapat pengaruh yang positif dan signifikan dari variabel strategi pemasaran dan komunikasi pemasaran terhadap kesadaran merek dan dampaknya pada minat menonton RCTI.
\end{abstract}

Kata kunci: strategi pemasaran, komunikasi pemasaran, kesadaran merek dan minat menonton 


\section{PENDAHULUAN}

Maraknya industri pertelevisian Indonesia saat ini ditandai dengan stasiun-stasiun televisi baru yang banyak bermunculan. Ada 11 stasiun televisi terestrial nasional yang memiliki operasi berbasis nasional (Media Scene, 2012-2013). Keseluruhan stasiun televisi tersebut adalah Rajawali Citra Televisi Indonesia (RCTI), Surya Citra Televisi (SCTV), INDOSIAR, ANTV, TransTV, Trans 7, MetroTV, TV One, Global TV, MNC TV, dan Televisi Republik Indonesia (TVRI). Selain stasiun televisi terestrial, ada juga stasiun televisi berjaringan antara lain B-Channel, Bali TV, City TV, Network Indonesia, Network JPMC, Kompas TV, SINDOtv, JakTV, Ochannel, TempoTV. Ada juga televisi kabel seperti Indovision, Telkomvision, dan Top TV yang menawarkan variasi program yang lebih spesifik.

RCTI adalah stasiun televisi swasta pertama di Indonesia. RCTI mulai mengudara secara terestrial di Jakarta. Saat ini RCTI merupakan stasiun televisi yang memiliki jangkauan terluas di Indonesia, melalui 48 stasiun relay-nya program-program RCTI disaksikan oleh lebih dari 190,4 juta pemirsa yang tersebar di 478 kota di seluruh Nusantara atau kira-kira 80,1\% dari jumlah penduduk Indonesia. Bisnis statsiun televise tidak jauh dengan yang istilah share dan rating. Rating TV adalah istilah yang mungkin sering anda dengar namun mungkin belum banyak dimengerti sepenuhnya. Rating TV adalah ukuran yang digunakan untuk menilai seberapa banyak tingkat atau presentase suatu acara TV ditonton oleh pemirsa pada saat ditayangkan. Dengan memasuki usianya yang ke-24, tahun 2013 (periode Januari-Desember 2013) RCTI tetap mempertahankan posisi market leader dengan pangsa pemirsa mencapai $17.5 \%$ (Menurut rating $\mathrm{ABC}, 5+$ ) dan $17.8 \%$ (Menurut rating All Demography). RCTI juga berhasil mempertahankan pangsa periklanan televisi tertinggi sebesar 15,7\% (periode Januari-Desember 2013), seperti dilaporkan oleh Nielsen Audience Measurement.

Walaupun RCTI masih tetap menjadi market leader pada industri pertelevisian, namun kehadiran stasiun-stasiun televisi swasta lain (Trans TV, Trans 7, MNC TV, dan lain-lain) menjadi ancaman serius bagi RCTI. Program-program acara yang ditawarkan tak kalah menarik dari RCTI. Kehadiran stasiun televisi lain tersebut memberi peluang bagi penonton untuk mencari alternatif tontonan menarik dan menghibur selain RCTI. Ini tentu menjadi masalah, jika RCTI tidak berupaya selalu menjaga dan meningkatkan kualitas program acara. Oleh karena RCTI perlu menjalankan strategi pemasaran dan komunikasi pemasaran yang tepat, agar dapat terus meningkatkan pangsa pasar dan menanamkan Brand Awareness yang kuat bagi pemirsa, sehingga mampu bersaing dan menumbuhkan minat menonton masyarakat serta menjadi stasiun televisi pilihan bagi pemirsa.

Menurut Kurtz (2008) strategi pemasaran adalah sebuah keseluruhan, program perusahaan untuk menentukan target pasar dan memuaskan konsumen dengan membangun kombinasi elemen dari bauran pemasaran, produk, distribusi, promosi dan harga. Sedangkan menurut Kotler \& Amstrong (2008), Strategi Pemasaran adalah logika pemasaran yang digunaskan unit bisnis untuk menciptakan nilai dan mendapatkan keuntungan dari hubungannya dengan konsumen. Integrated Marketing Communication menurut Duncan (2005) adalah sebuah kumpulan berbagai pesan yang telah dirancang untuk membangun suatu brand. Kumpulan berbagai pesan tersebut antara lain adalah iklan, pemasaran langsung, internet marketing, promosi penjualan, publisitas dan penjualan secara individu. Sedangkan menurut Kotler (2008) IMC adalah sebuah konsep yang digunakan perusahaan dengan hati-hati mengintegrasikan dan mengkoordinasikan saluran-saluran komunikasi dengan tujuan untuk menyampaikan dengan jelas, konsisten pesan mengenai perusahaan dan produk-produknya. Harsono Suwardi menyatakan bahwa dasar dari pemasaran adalah komunikasi dan pemasaran bisa akan begitu powerful jika dipadukan dengan komunikasi yang efektif dan efisien. Bagaimana menarik konsumen atau khalayak menjadi aware, kenal dan mau membeli suatu produk atau jasa melalui saluran komunikasi adalah bukan sesuatu yang mudah (Prisgunanto, 2006). 
Menurut Durianto, Sugiarto dan Sitinjak (2004), Kesadaran Merek adalah kesanggupan seorang calon pembeli untuk mengenali dan mengingat kembali suatu merek sebagai bagian dari suatu kategori produk tertentu.

Jika kesadaran dalam benak konsumen sangat rendah, maka hampir dipastikan bahwa ekuitas mereknya juga rendah. Brand awareness yang tinggi dapat meningkatkan familiarity yang positif sehingga dapat masuk dalam list brand untuk dibeli. Kesadaran (awareness) menggambarkan kesadaran merek dalam pikiran konsumen yang dapat menjadi penentu dalam beberapa kategori dan mempunyai peranan kunci dalam brand equity.

Menurut kamus lengkap psikologi, Minat (interest) adalah (1) Satu sikap yang berlangsung terus menerus yang memolakan perhatian seseorang, sehingga membuat dirinya jadi selektif terhadap objek minatnya. (2) Perasaan yang menyatakan bahwa satu aktivitas, pekerjaan, atau objek itu berharga atau berarti bagi individu. (3) Satu keadaan motivasi, atau satu set motivasi yang menuntun tingkah laku menuju satu arah (sasaran) tertentu (dalam Chaplin, 2008).

Rast, Harmin dan Simon (dalam Mulyati, 2004) menyatakan bahwa dalam minat itu terdapat hal-hal pokok diantaranya: (1) Adanya perasaan senang dalam diri yang memberikan perhatian pada objek tertentu. (2) Adanya ketertarikan terhadap objek tertentu. (3) Adanya aktivitas atas objek tertentu. (4) Adanya kecenderungan berusaha lebih aktif. (5) Objek atau aktivitas tersebut dipandang fungsional dalam kehidupan. (6) Kecenderungan bersifat mengarahkan dan mempengaruhi tingkah laku individu.

Sebagai bahan pertimbangan peneliti dalam menyusun penelitian ini, maka akan dijelaskan mengenai penelitian terdahulu yang relevan sesuai dengan jenis variabel yang akan diteliti yaitu hubungan Strategi Pemasaran, Marketing Communication, dan Brand Awareness terhadap Minat Menonton. Budacia (2008) mengambil objek penelitian channel televisi di Rumania yang hanya menyiarkan HBO channel sebagai televisi berbayar di sana. Hasil analisa menunjukkan bahwa kebijakan (policy) yang berkaitan dengan product, price (hanya untuk HBO yang berbayar), distribution, promotion, and celebrity marketing adalah strategi yang harus dijalankan dengan tepat oleh channel televisi. Brunello (2013) fokus pada pentingnya komunikasi pemasaran baik untuk konsumen dan perusahaan. Saat ini mengimplementasikan strategi IMC memainkan suatu peran dalam membujuk konsumen untuk membeli produk atau jasa perusahaan. Tetapi IMC memiliki lebih banyak nilai signifikan: IMC berkontribusi pada pengembangan suatu ekuitas merek perusahaan. Malik (2013) membahas tentang pengaruh Brand Awareness dan Brand Loyalty terhadap Minat Membeli. Kuisioner dibagikan untuk mengumpulkan tanggapan dari karyawan disektor jasa dan masyarakat umum mudah tersedia sementara statistik deskriptif dan analisis regresi digunakan untuk menganalisis data dan menarik kesimpulan.

Artikel ini berdasarkan data bahan penelitian yang diperoleh melalui beberapa pertanyaan untuk dijadikan rumusan masalah. Perumusan masalah yang diajukan dicari penjelasan serta jawabannya adalah sebagai berikut: (1) Bagaimana pengaruh Strategi Pemasaran terhadap Brand Awareness? (2) Bagaimana pengaruh Marketing Communication terhadap Brand Awareness? (3) Bagaimana pengaruh Strategi Pemasaran terhadap Minat Menonton RCTI? (4) Bagaimana pengaruh Marketing Communication terhadap Minat Menonton RCTI? (5) Bagaimana pengaruh Brand Awareness terhadap Minat Menonton RCTI? (6) Bagaimana pengaruh Strategi Pemasaran dan Marketing Communication terhadap Brand Awareness? (7) Bagaimana pengaruh Strategi Pemasaran, Marketing Communication terhadap Brand Awareness dan dampaknya pada Minat Menonton RCTI?

Tujuan penelitian yang ingin dicapai adalah sebagai berikut: (1) Untuk mengetahui adakah pengaruh Strategi Pemasaran terhadap Brand Awareness. (2) Untuk mengetahui adakah pengaruh Marketing Communication terhadap Brand Awareness. (3) Untuk mengetahui adakah pengaruh Strategi Pemasaran terhadap Minat Menonton RCTI. (4) Untuk mengetahui adakah pengaruh 
Marketing Communication terhadap Minat Menonton RCTI. (5) Untuk mengetahui adakah pengaruh Brand Awareness terhadap Minat Menonton RCTI. (6) Untuk mengetahui adakah pengaruh Strategi Pemasaran dan Marketing Communication terhadap Brand Awareness. (7) Untuk mengetahui adakah pengaruh Strategi Pemasaran, Marketing Communication terhadap Brand Awareness dan dampaknya pada Minat Menonton RCTI.

RCTI diharapkan dapat mengetahui Strategi Pemasaran dan Marketing Communication yang berperan penting dalam membentuk suatu Brand Awareness yang menjadi faktor utama dalam menarik minat masyarakat untuk menonton RCTI. Bagi pembaca dapat memberikan gambaran secara umum aktivitas pemasaran dalam pertelevisian dan memperluas pemahaman tentang Strategi Pemasaran, Marketing Communication dan Brand Awareness. Artikel ini diharapkan bisa memberikan informasi sebagai bahan masukan ataupun referensi tambahan yang khusunya pada masalah Strategi Pemasaran dan Marketing Communication terhadap Brand Awareness dan dampaknya pada Minat Menonton, sehingga dapat berguna bagi peneliti lain.

Penelitian ini berdasarkan penelitian terdahulu dan secara teoritis, maka kerangka model konseptual dalam penelitian ini adalah sebagai berikut:

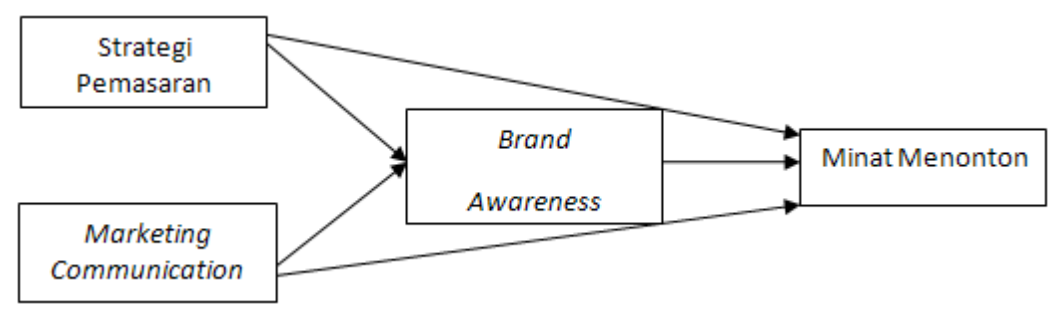

Gambar 1 Model Kerangka Konseptual

\section{METODE}

\section{Desain Penelitian}

Jenis penelitian yang digunakan untuk penelitian ini adalah Penelitian Asosiatif. Penelitian Asosiatif merupakan suatu jenis penelitian yang bertujuan untuk mengetahui hubungan antar dua variabel atau lebih yang ingin diteliti. Sehingga dapat dibangun suatu teori yang dapat berfungsi menjelaskan variabel yang diteliti. Time Horizon yang dipakai adalah cross sectional, yaitu data yang dikumpulkann pada suatu waktu tertentu untuk menggambarkan keadaan fakta yang bersangkutan (Supranto, 2003).

Tabel 1 Desain Penelitian

\begin{tabular}{cccc}
\hline Tujuan & $\begin{array}{c}\text { Jenis dan Metode } \\
\text { Penelitian }\end{array}$ & Unit Analisis & Time Horizon \\
\hline T-1 & Asosiatif- Suvey & Individu & Crosssectional \\
T-2 & Asosiatif- Suvey & Individu & Crosssectional \\
T-3 & Asosiatif- Suvey & Individu & Crosssectional \\
T-4 & Asosiatif- Suvey & Individu & Crosssectional \\
T-5 & Asosiatif- Suvey & Individu & Crosssectional \\
T-6 & Asosiatif- Suvey & Individu & Crosssectional \\
T-7 & Asosiatif- Suvey & Individu & Crosssectional \\
\hline
\end{tabular}




\section{Jenis dan Sumber Data}

Data-data yang dibutuhkan dalam penelitian ini terdiri dari data primer dan data sekunder. Data Primer adalah data yang dikumpulkan dan diolah sendiri oleh perorangan langsung dari objeknya. Data primer pada penelitian ini didapatkan dari pengamatan langsung menggunakan kuisioner pada masyarakat umum (Supranto 2003). Data Sekunder adalah data yang diperoleh dalam bentuk sudah jadi, sudah dikumpulkan dan diolah oleh pihak lain. Dalam hal ini adalah data yang diperoleh dari RCTI yang mendukung penelitian (Supranto 2003).

\section{Tehnik Pegumpulan Data}

Tehnik pengumpulan data yang dilakukan oleh peneliti adalah sebagai berikut: (1) Studi Pustaka. Ini adalah tehnik mengumpulkan data sekunder yang berhubungan dengan penelitian, sehingga dapat membantu proses penelitian ini. Data ini diambil dengan cara membaca buku yang relevan dengan topik penelitian serta mengkaji data dari jurnal dan thesis yang berkaitan pula. (2) Penelitian Lapangan. Penelitian lapangan berguna untuk menghimpun data secara langsung, melalui metode kuesioner dan wawancara.

Kuisioner adalah satu set pertanyaan yang tersusun secara sistematis dan standar, sehingga pertanyaan yang sama dapat diajukan terhadap setiap responden. Tehnik pengumpulan data dengan cara menyebar kuisioner kepada masyarakat umum. Daftar pertanyaan sesuai dengan topik penelitian dan penjabaran variabel-variabel yang digunakan yaitu Strategi Pemasaran (X1), Marketing Communication (X2), Brand Awareness (Y) dan Minat Menonton (Z) (Supranto, 2003). Indikator yang dipakai untuk mengukur respon terhadap setiap butir pertanyaan menggunakan skala likert 5 item yaitu Sangat Tidak Setuju, Tidak Setuju, Netral, Setuju, Sangat Setuju. Dengan bobot nilai seperti berikut:

Tabel 2 Bobot Nilai Kuisioner

\begin{tabular}{cc}
\hline Jawaban Responden & Bobot Nilai \\
\hline Sangat Setuju & 5 \\
Setuju & 4 \\
Netral & 3 \\
Tidak Setuju & 2 \\
Sangat Tidak Setuju & 1 \\
\hline
\end{tabular}

Tehnik wawancara digunakan untuk mendapatkan data sekunder dari perusahaan langsung. Ini dilakukan dengan izin langsung dari Senior Manager RCTI demi kebutuhan penelitian.

\section{Populasi dan Sampel}

Nariwati, Umi dan Munandar, Dadang (2008), Sampling adalah merupakan suatu praktik statistik yang berhubungan dengan pemilihan observasi individual yang ditujukan untuk memahami populasi yang terkait. Tehnik memilih atau mengambil sampel yang terdapat dalam populasi dan harus benar-benar mewakili dan menggambarkan keadaaan populasi yang sebenarnya. Yang dipakai untuk pengambilan sampel adalah probability sampling dengan tehnik simple random sampling. Salah satu cara adalah mengambil sampel secara random yang telah ditentukan lokasinya. Dilakukan agar sampel yang diambil ditentukan lokasinya tetapi diacak penyebarannya tanpa memperhatikan tingkatan anggota populasi. 
Teknik yang cukup penting dalam penelitian adalah pengolahan data. Pengolahan data bermaksud untuk mengungkap hasil akhir penelitian dari data yang telah diperoleh. Pengolahan data dilakukan melalui bantuan komputer dengan program SPSS (Statistical Product and Service Solution). Setelah data dikumpulkan, maka uji validitas-reliabilitas, lalu dilakukan uji normalitas terhadap data yang ada. Setelah data dipastikan normal, valid, dan reliabel, maka dilakukan analisis dengan menggunakan tehnik analisis seperti dapat dilihat pada Tabel 3 di bawah ini.

Tabel 3 Metode Analisis

\begin{tabular}{ccc}
\hline \multirow{2}{*}{$\begin{array}{c}\text { Tujuan } \\
\text { Penelitian }\end{array}$} & \multicolumn{2}{c}{ Metode Analisis } \\
\cline { 2 - 3 } & Jenis Penelitian & \multicolumn{1}{c}{ Teknik Analisis } \\
\hline T-1 & Asosiasif & Path Analysis dan Pearson Correlation \\
T-2 & Asosiasif & Path Analysis dan Pearson Correlation \\
T-3 & Asosiasif & Path Analysis dan Pearson Correlation \\
T-4 & Asosiasif & Path Analysis dan Pearson Correlation \\
T-5 & Asosiasif & Path Analysis dan Pearson Correlation \\
T-6 & Asosiasif & Path Analysis dan Pearson Correlation \\
T-7 & Asosiasif & Path Analysis dan Pearson Correlation \\
\hline
\end{tabular}

\section{HASIL DAN PEMBAHASAN}

\section{Analisis Jalur Sub-Struktur 1}

Adapun gambar dari sub-struktur 1 tersebut dapat dilihat pada Gambar 2:

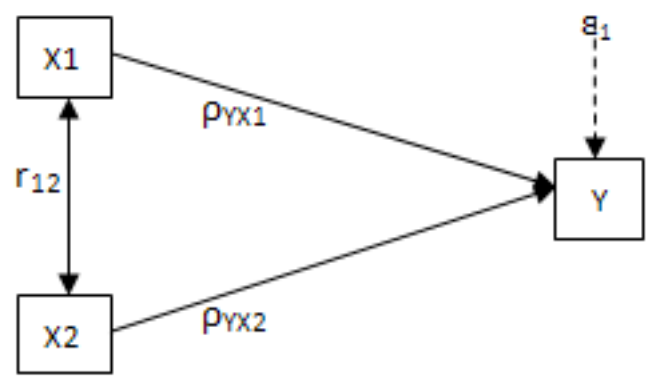

Gambar 2 Hubungan Sub-Struktur X1 dan X2, Terhadap Y

Selanjutnya, dengan menggunakan bantuan program SPSS, analisa data X1, X2, dan Y memperoleh hasil output (Tabel 4 - Tabel 7): 
Tabel 4 Korelasi Pearson X1, X2, Y dan Z

Correlations

\begin{tabular}{|c|c|c|c|c|c|}
\hline & & $\begin{array}{c}\text { Strategi } \\
\text { Pemasaran }\end{array}$ & $\begin{array}{c}\text { Marketing } \\
\text { Communi } \\
\text { cation }\end{array}$ & $\begin{array}{c}\text { Brand } \\
\text { Awareness }\end{array}$ & $\begin{array}{c}\text { Minat } \\
\text { Menonton }\end{array}$ \\
\hline & \multirow{2}{*}{1} & $.414^{* 1}$ & $.741^{*}$ & $.631^{*}$ \\
\hline \multirow{2}{*}{ Strategi Pemasar } & \multirow{2}{*}{$\begin{array}{l}\text { Pearson Correlati } \\
\text { Sig. (2-tailed) } \\
\mathrm{N}\end{array}$} & & .000 & .000 & .000 \\
\hline & & 100 & 100 & 100 & 100 \\
\hline \multirow{3}{*}{$\begin{array}{l}\text { Marketing } \\
\text { Communication }\end{array}$} & Pearson Correlati & $.414^{*}$ & \multirow[t]{2}{*}{1} & $.480 *$ & $.796^{*}$ \\
\hline & Sig. (2-tailed) & .000 & & .000 & .000 \\
\hline & $\mathrm{N}$ & 100 & 100 & 100 & 100 \\
\hline \multirow[t]{3}{*}{ Brand Awareness } & Pearson Correlati & $.741^{*}$ & $.480 *$ & \multirow[t]{2}{*}{1} & $.690 *$ \\
\hline & Sig. (2-tailed) & .000 & .000 & & .000 \\
\hline & $\mathrm{N}$ & 100 & 100 & 100 & 100 \\
\hline \multirow[t]{3}{*}{ Minat Menonton } & Pearson Correlati & $.631^{*}$ & $.796 *$ & $.690 *$ & \multirow[t]{2}{*}{1} \\
\hline & Sig. (2-tailed) & .000 & .000 & .000 & \\
\hline & $\mathrm{N}$ & 100 & 100 & 100 & 100 \\
\hline
\end{tabular}

${ }^{\star \star}$. Correlation is significant at the 0.01 level (2-tailed).

Sumber: Hasil Output SPSS, 2014

Tabel 5 Anova Sub-Struktur 1

ANOVA

\begin{tabular}{|ll|r|r|r|r|r|}
\hline Model & & \multicolumn{1}{c|}{$\begin{array}{c}\text { Sum of } \\
\text { Squares }\end{array}$} & df & Mean Square & F & Sig. \\
\hline 1 & Regression & 1288.195 & 2 & 644.097 & 68.498 & $.000^{\mathrm{a}}$ \\
& Residual & 912.104 & 97 & 9.403 & & \\
& Total & 2200.298 & 99 & & & \\
\hline
\end{tabular}

a. Predictors: (Constant), Marketing Communication, Strategi Pemasaran

b. Dependent Variable: Brand Awareness

Sumber: Hasil Output SPSS, 2014

Tabel 6 Coefficients Sub-Struktur 1

Coefficients

\begin{tabular}{|c|c|c|c|c|c|c|}
\hline \multirow[b]{2}{*}{ Mode } & & \multicolumn{2}{|c|}{$\begin{array}{l}\text { Unstandardized } \\
\text { Coefficients }\end{array}$} & \multirow{2}{*}{\begin{tabular}{|c|c|}
$\begin{array}{c}\text { Standardized } \\
\text { Coefficients }\end{array}$ \\
$\mathrm{r}$ & Beta
\end{tabular}} & \multirow[b]{2}{*}{$\mathrm{t}$} & \multirow[b]{2}{*}{ Sig. } \\
\hline & & B & Std. Error & & & \\
\hline \multirow[t]{3}{*}{1} & (Constant) & 10.558 & 1.635 & & 6.459 & .000 \\
\hline & Strategi Pemasa & .787 & .086 & .655 & 9.116 & .000 \\
\hline & $\begin{array}{l}\text { Marketing } \\
\text { Communication }\end{array}$ & .170 & .059 & 209 & 2.913 & .004 \\
\hline
\end{tabular}

a. Dependent Variable: Brand Awareness

Sumber: Hasil Output SPSS, 2014 
Tabel 7 Model Summary Sub-Struktur 1

Model Summary
\begin{tabular}{|l|l|r|r|c|}
\hline Model & R & R Square & $\begin{array}{c}\text { Adjusted } \\
\text { R Square }\end{array}$ & $\begin{array}{c}\text { Std. Error of } \\
\text { the Estimate }\end{array}$ \\
\hline 1 & $.765^{\mathrm{a}}$ & .585 & .577 & 3.06645 \\
\hline
\end{tabular}
a. Predictors: (Constant), Marketing Communicatio
Strategi Pemasaran

Sumber: Hasil Output SPSS, 2014

\section{Analisis Sub-Struktur 2}

Pengujian sub-struktur 2 ini terdiri dari variabel Strategi Pemasaran, Marketing Communication sebesar satu, maka Brand Awareness, Minat Menonton yang digambarkan dalam bentuk berikut ini:

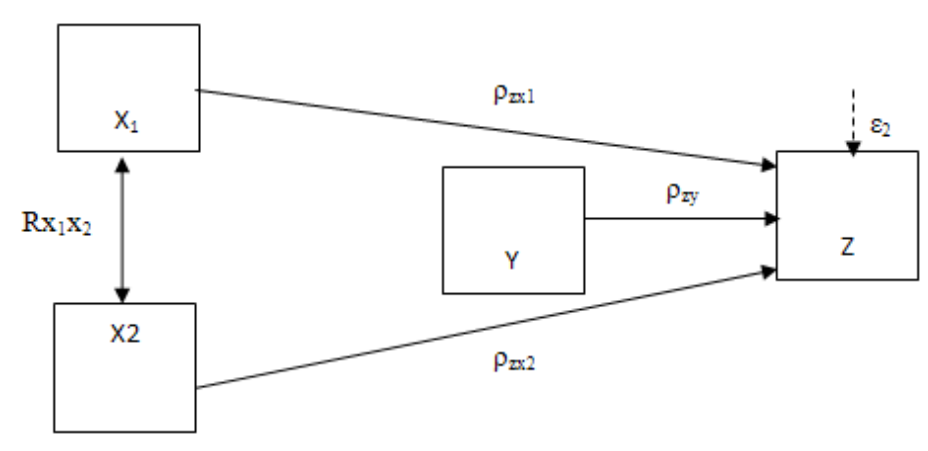

Gambar 3 Hubungan Sub-Struktur 2 Variabel X1, X2, Y, Terhadap Z

Sub-struktur 2 dianalisa menggunakan analisis jalur, selanjutnya dengan menggunakan program SPSS, analisa atas sub-struktur 2 menghasilkan output sebagai berikut:

Tabel 8 Korelasi Pearson Variabel X1, X2, Y, dan Z

Correlations

\begin{tabular}{|c|c|c|c|c|c|}
\hline & & $\begin{array}{c}\text { Strategi } \\
\text { Pemasaran }\end{array}$ & $\begin{array}{c}\text { Marketing } \\
\text { Communi } \\
\text { cation }\end{array}$ & $\begin{array}{c}\text { Brand } \\
\text { Awareness }\end{array}$ & $\begin{array}{c}\text { Minat } \\
\text { Menonton }\end{array}$ \\
\hline \multicolumn{2}{|c|}{ Strategi Pemasar. Pearson Correlati } & \multirow[t]{2}{*}{1} & $.414^{* * 1}$ & $.741^{\star *}$ & $.631^{\star}$ \\
\hline \multirow{2}{*}{\multicolumn{2}{|c|}{$\begin{array}{l}\text { Sig. (2-tailed) } \\
\mathrm{N}\end{array}$}} & & .000 & .000 & .000 \\
\hline & & 100 & 100 & 100 & 100 \\
\hline \multirow{3}{*}{$\begin{array}{l}\text { Marketing } \\
\text { Communication }\end{array}$} & Pearson Correlat & $.414^{*}$ & \multirow[t]{2}{*}{1} & $.480 *$ & $.796^{\star}$ \\
\hline & Sig. (2-tailed) & .000 & & .000 & .000 \\
\hline & $\mathrm{N}$ & 100 & 100 & 100 & 100 \\
\hline \multirow[t]{3}{*}{ Brand Awareness } & Pearson Correlat & $.741 *$ & $.480^{* * 1}$ & 1 & $.690^{\star}$ \\
\hline & Sig. (2-tailed) & .000 & .000 & & .000 \\
\hline & $\mathrm{N}$ & 100 & 100 & 100 & 100 \\
\hline \multirow[t]{3}{*}{ Minat Menonton } & Pearson Correlat & $.631 *$ & $.796 * 1$ & $.690 * 1$ & 1 \\
\hline & Sig. (2-tailed) & .000 & .000 & .000 & \\
\hline & $\mathrm{N}$ & 100 & 100 & 100 & 100 \\
\hline
\end{tabular}

${ }^{\star \star}$. Correlation is significant at the 0.01 level (2-tailed).

Sumber: Hasil Output SPSS, 2014 
Tabel 9 Anova Sub-Struktur 2

ANOVA $^{\text {b }}$

\begin{tabular}{|c|c|c|c|c|c|c|}
\hline \multicolumn{2}{|c|}{ Model } & $\begin{array}{l}\text { Sum of } \\
\text { Squares }\end{array}$ & $d f$ & Mean Square & $\mathrm{F}$ & Sig. \\
\hline \multirow[t]{3}{*}{1} & Regression & 785.054 & 3 & 261.685 & 108.467 & $.000^{\mathrm{a}}$ \\
\hline & Residual & 231.607 & 96 & 2.413 & & \\
\hline & Total & 1016.661 & 99 & & & \\
\hline
\end{tabular}

a. Predictors: (Constant), Brand Awareness, Marketing Communication, Strategi Pemasaran

b. Dependent Variable: Minat Menonton

Sumber: Hasil Output SPSS, 2014

Tabel 10 Coefficients Sub-Struktur 2

\begin{tabular}{|rl|r|r|r|r|r|}
\hline \multicolumn{1}{|c|}{} & \multicolumn{2}{|c|}{$\begin{array}{c}\text { Unstandardized } \\
\text { Coefficients }\end{array}$} & $\begin{array}{c}\text { Standardized } \\
\text { Coefficients }\end{array}$ & & \\
\cline { 3 - 5 } Model & \multicolumn{1}{|c|}{ B } & Std. Error & \multicolumn{1}{c|}{ Beta } & \multicolumn{1}{c|}{ t } & \multicolumn{1}{c|}{ Sig. } \\
\hline 1 & (Constant) & -2.939 & .990 & & -2.969 & .004 \\
& Strategi Pemasaran & .155 & .060 & .189 & 2.594 & .011 \\
& Marketing & .326 & .031 & .589 & 10.563 & .000 \\
& Communication & .181 & .051 & .267 & 3.525 & .001 \\
\hline
\end{tabular}

a. Dependent Variable: Minat Menonton

Sumber: Hasil Output SPSS, 2014

Tabel 11 Model Summary Sub-Struktur 2

\begin{tabular}{|l|r|r|r|r|}
\multicolumn{6}{|c|}{ Model Summary } \\
\hline Model & R & R Square & $\begin{array}{c}\text { Adjusted } \\
\text { R Square }\end{array}$ & $\begin{array}{c}\text { Std. Error of } \\
\text { the Estimate }\end{array}$ \\
\hline 1 & $.879^{\mathrm{a}}$ & .772 & .765 & 1.55325 \\
\hline
\end{tabular}

a. Predictors: (Constant), Brand Awareness, Marketing Communication, Strategi Pemasaran

Sumber: Hasil Output SPSS, 2014

\section{Hasil}

Berdasarkan analisis yang dilakukan, dapat dibuat suatu rangkuman akan besar pengaruh dari variabel eksogenus terhadap variabel endogenus baik secara parsial maupun simultan, yang dapat dilihat pada Tabel 12 berikut ini:

Tabel 12 Rangkuman Hubungan Kausal Empiris Variabel X1, X2, dan Y Terhadap Z

\begin{tabular}{ccccc}
\hline & & \multicolumn{3}{c}{ Pengaruh } \\
\cline { 3 - 5 } Variabel & Koefisien Jalur & Langsung & $\begin{array}{c}\text { Tidak Langsung } \\
\text { (Melalui Variabel Y) }\end{array}$ & Total \\
\hline $\mathrm{X}_{1}$ terhadap Y & & 0,655 & - & 0,655 \\
$\mathrm{X}_{1}$ terhadap Z & 0,189 & 0,189 & $0,655 \times 0,267=0,175$ & 0.364 \\
$\mathrm{X}_{2}$ terhadap Y & 0,209 & 0,209 & - & 0,209 \\
$\mathrm{X}_{2}$ terhadap Z & 0,589 & 0,589 & $0,317 \times 0,262=0,083$ & 0,672 \\
Y terhadap Z $_{\varepsilon_{1}}$ & 0,267 & 0,267 & - & 0,267 \\
$\varepsilon_{2}$ & 0,414 & - & - & - \\
\hline
\end{tabular}

Sumber: Hasil Olahan Penulis 
Pengaruh langsung, tidak langsung, dan pengaruh total dibahas sebagai berikut: (1) Penerapan Strategi Pemasaran $\left(\mathrm{X}_{1}\right)$ secara langsung mempengaruhi Brand Awareness $(\mathrm{Y})$ sebesar $(0,655)^{2}=$ 0,429 atau $42,9 \%$ dan sisanya sebesar $57,1 \%$ dipengaruhi oleh faktor lain diluar penelitian ini. (2) Penerapan Strategi Pemasaran $\left(\mathrm{X}_{1}\right)$ secara langsung mempengaruhi Minat Menonton $(\mathrm{Z})$ sebesar $(0,189)^{2}=0,036$ atau $3,6 \%$ dan sisanya sebesar $96,4 \%$ dipengaruhi faktor lain diluar penelitian ini. (3) Penerapan Strategi Pemasaran $\left(\mathrm{X}_{1}\right)$ secara tidak langsung mempengaruhi Minat Menonton $(\mathrm{Z})$ melalui Brand Awareness $(\mathrm{Y})$ dengan pengaruh total sebesar $(0,364)^{2}=0,132$ atau $13,2 \%$ dan sisanya sebesar $86,8 \%$ dipengaruhi faktor lain diluar penelitian ini.

Dari hasil Tabel 12 dan keterangan No. 1, 2 dan 3 di atas menunjukkan bahwa pengaruh Strategi Pemasaran secara langsung terhadap Brand Awareness dan secara tidak langsung terhadap Minat Menonton masih kurang. Oleh karena itu RCTI perlu meningkatkan lagi Strategi Pemasaran seperti dalam menerapkan strategi Marketing Mix (product, place, price, promotion) serta dalam STPD (segmenting, targeting, positioning, differentiation) pada program-program acara RCTI.

Penerapan Marketing Communication $\left(\mathrm{X}_{2}\right)$ secara langsung mempengaruhi Brand Awareness (Y) sebesar $(0,209)^{2}=0,044$ atau $4,4 \%$ dan sisanya sebesar $95,6 \%$ dipengaruhi oleh faktor lain di luar penelitian ini.

Penerapan Marketing Communication $\left(\mathrm{X}_{2}\right)$ secara langsung mempengaruhi Minat Menonton $(Z)$ sebesar $(0,589)^{2}=0,347$ atau $34,7 \%$ dan sisanya sebesar $65,3 \%$ dipengaruhi faktor lain di luar penelitian ini.

Penerapan Marketing Communication $\left(\mathrm{X}_{2}\right)$ secara tidak langsung mempengaruhi Minat Menonton ( $\mathrm{Z}$ ) melalui Brand Awareness (Y) dengan pengaruh total sebesar $(0,672)^{2}=0,452$ atau $45,2 \%$ dan sisanya sebesar $54,8 \%$ dipengaruhi faktor lain di luar penelitian ini.

Dari hasil Tabel 12 dan keterangan No.4, 5, dan 6 di atas menunjukkan bahwa pengaruh Marketing Communication secara langsung terhadap Brand Awareness dan secara tidak langsung terhadap Minat Menonton masih kurang. Oleh karena itu RCTI perlu mengkomunikasikan dengan baik program-program acara mereka lewat berbagai macam media massa dan elektronik.

Penerapan Brand Awareness (Y) secara langsung mempengaruhi Minat Menonton (Z) sebesar $(0,267)^{2}=0,071$ atau $7,1 \%$ dan sisanya sebesar $92,9 \%$ dipengaruhi faktor lain di luar penelitian ini.

Dari hasil Tabel 12 dan keterangan No.7 di atas menunjukkan bahwa pengaruh langsung Brand Awareness terhadap Minat Menonton masih kurang. Oleh karena itu RCTI perlu meningkatkan Brand Awareness penonton dengan membuat program-program acara yang dapat menimbulkan citra (image) yang baik untuk RCTI di benak masyarakat.

\section{SIMPULAN}

Dari hasil penelitian yang telah dilakukan terhadap variabel Strategi Pemasaran (X1), variabel Marketing Communication (X2), variabel Brand Awareness (Y), dan juga variabel Minat Menonton (Z) dengan menggunakan bantuan aplikasi software SPSS versi 16 dan dengan perhitungan analisis jalur struktural, maka diperoleh kesimpulan dari hubungan kausal variabel-variabel tersebut, yaitu: (1) Terdapat pengaruh positif dan signifikan antara Strategi Pemasaran terhadap Brand Awareness. (2) Terdapat pengaruh positif dan signifikan antara Marketing Communication terhadap Brand Awareness. (3) Terdapat pengaruh positif dan signifikan antara Strategi Pemasaran terhadap Minat 
Menonton RCTI. (4) Terdapat pengaruh positif dan signifikan antara Marketing Communication terhadap Minat Menonton RCTI. (5) Terdapat pengaruh positif dan signifikan antara Brand Awareness terhadap Minat Menonton RCTI. (6) Terdapat pengaruh positif dan signifikan antara Strategi Pemasaran dan Marketing Communication terhadap Brand Awareness. (7) Terdapat pengaruh positif dan signifikan antara Strategi Pemasaran, Marketing Communication, dan Brand Awareness terhadap Minat Menonton RCTI.

Berdasarkan penelitian yang sudah dilakukan oleh penulis, ada beberapa saran yang dapat diberikan kepada RCTI, yaitu sebagai berikut: (1) RCTI harus menayangkan program acara baru berupa variety show yang menghibur dan kreatif pada jam prime time. (2) Program CSR berupa RCTI peduli yang dilakukan oleh public relation RCTI dapat menimbulkan citra yang baik untuk RCTI di benak masyarakat, oleh karena itu program ini perlu dipertahankan dan terus dijalankan. (3) RCTI diharapkan dapat mempromosikan dengan baik program-program acara mereka dan memberikan informasi jadwal tayang acara tersebut lewat iklan, event, dan pemasaran internet.

\section{DAFTAR PUSTAKA}

Brunello, A. (2013). The relationship between Integrated Marketing Communication and Brand Equity. Outlook on Communication: 9-14.

Budacia, E. A. (2008). The specifics Marketing Mix strategies in television. Romanian Economic and Business Review. 3(1): 64-73.

Chaplin, J. P. (2008). Kamus Psikologi Lengkap. Jakarta: PT Raja Grafindo.

Duncan, T. (2005). IMC: Using Advertising \& Promotion to build brands. New York: The McGrawHill Companies.

Durianto, D., Sugiarto. (2004). Brand Equity ten: Strategi memimpin pasar. Gramedia Pustaka Utama.

Kotler, P., Amstrong, G. (2008). Principles of Marketing. Twelve Edition, Pearson.

Kotler, P. (2008). Manajemen Pemasaran. Jilid 1. Edisi keduabelas. Jakarta: Indeks Kelompok PT. Gramedia.

Kurtz, D. L. (2008). Principles of contemporary Marketing. Stamford: Educational Publishing,.

Malik, M. E., Ghafoor, M. M., Hafiz, K. I., Riaz, U., Hassan, U. I. (2013). Importance of brand awareness and brand loyalty in assessing purchase intentions of consumer. International Journal of Business and Social Science, 4(5).

Mulyati. (2004). Psikologika. Jurnal Pemikiran dan Penelitian Psikologi, 18. Yogyakarta: Fakultas Psikologi Universitas Islam Indonesia.

Narimawati, U., Munandar, D. (2008). Tehnik sampling: Teori dan praktik dengan SPSS 15. Yogyakarta: Gava Media.

Prisgunanto, I. (2006). Komunikasi Pemasaran: Strategi dan taktik. Bogor: Ghalia Indonesia.

Supranto, J. (2003). Metode riset dan aplikasinya dalam riset Pemasaran, Edisi Revisi. Jakarta: Lembaga Penerbit Fakultas Ekonomi UI. 